PNL-3231

UC-94b

\title{
Structural Analysis of Porous \\ Rock Reservoirs Subjected to Conditions of Compressed Air Energy Storage
}

\author{
J. R. Friley
}

January 1980

Prepared for the U.S. Department of Energy under Contract EY-76-C-06-1830

Pacific Northwest Laboratory Operated for the U.S. Department of Energy by Battelle Memorial Institute 


\title{
NOTICE
}

This report was prepared as an account of work sponsored by the United States Government. Neither the United States nor the Department of Energy, nor any of their employees, nor any of their contractors, subcontractors, or their employees, makes any warranty, express or implied, or assumes any legal liability or responsibility for the accuracy, completeness or usefulness of any information, apparatus, product or process disclosed, or represents that its use would not infringe privately owned rights.

The views, opinions and conclusions contained in this report are those of the contractor and do not necessarily represent those of the United States Government or the United States Department of Energy.

\author{
PACIFIC NORTHWEST LABORATORY \\ operated by \\ BATTELLE \\ for the \\ UNITED STATES DEPARTMENT OF ENERGY \\ Under Contract EY-76-C-06-7830
}
Primted in the United States of America Available from
National Technical Information Service
United States Department of Commerce
5285 Port Royal Road
Springfield, Virginia 22151

Price: Printed Copy $\$$

$\approx$ : Microfiche $\$ 3.00$

$\begin{array}{cc}\text {-Pages } & \begin{array}{c}\text { NTIS } \\ \text { Selling Price }\end{array} \\ 001-025 & \$ 4.00 \\ 026-050 & 54.50 \\ 051-075 & 55.25 \\ 076-100 & 56.00 \\ 101-125 & 56.50 \\ 126-150 & 57.25 \\ 151-175 & 58.00 \\ 176-200 & \$ 9.00 \\ 201-225 & 59.25 \\ 226-250 & 59.50 \\ 251-275 & 510.75 \\ 276-300 & 511.00\end{array}$


J. R. Fritey

January 1980

Prepared for the U.S. Department of Energy under Contract EY-76-C-06-1830

Pacific Northwest Laboratory

Richland, Washington 99352 



\section{FOREWORD}

The Compressed Air Energy Storage Technology Program at the Pacific Northwest Laboratory (PNL) is sponsored by the Department of Energy, Division of Energy Storage Systems. The program scope includes a group of studies directed at developing a new energy storage technology to improve the cost and efficiency of electrical power utilization and reducing the dependence on petroleum fuels such as oil and natural gas. The program has two major thrusts --- Reservoir Stability Criteria Studies and Advanced Concepts Studies. These have the following objectives:

- Reservoir Stability Criteria

Develop design and stability criteria for long-term operation of underground reservoirs used for compressed air energy storage (CAES) in order to accelerate the commercialization of the concept.

- Advanced Concepts Studies

Develop and assess advanced CAES concepts that require little or no supplementary firing by petroleum fuels in order to eliminate the dependence of CAES on petroleum fuels.

The ultimate objective of this program is to reduce the consumption of natural gas and $0 i 1$ used for peak-power generation plants by about $100,000,000$ barrels per year. This could be accomplished by replacing conventional gas turbine peaking plants currently being used by utilities with CAES plants.

The following documents have been issued by PNL or by subcontractors to PNL, reporting the results of the work toward these objectives.

- Air Storage Peaking Power Plants Utilizing Modified Industrial Gas Turbines and Cavities with Nuclear Explosives, B.C. Fryer, BNWL-1748, May 1973.

- Technical and Economic Feasibility Analysis of the No-Fuel Compressed Air Energy Storage Concept, D.K. Kreid, BNWL-2065, May 1976. 
- FY-1977 Progress Report - Stability and Design Criteria Studies for Compressed Air Energy Storage Reservoirs, G.C. Smith, J.A. Stottlemyre, L.E. Wiles, W.V. Loscutoff and H.J. Pincus, PNL-2443 March 1978.

- FY-1977 Progress Report Compressed Air Energy Storage Advanced Systems Analysis, D.K. Kreid and M.A. McKinnon, PNL-2464, March 1978.

- Preliminary Stability Criteria for Compressed Air Energy Storage in Porous Media Reservoirs, J.A. Stottlemyre, PNL-2685, June 1978.

- Prel iminary Long-Term Stability Criteria for Compressed Air Energy Storage Caverns in Salt Domes, R.L. Thoms and J.D. Martinez, PNL-2871, August 1978.

- Numerical Analysis of Temperature and Flow Effects in a Dry, OneDimensional Aquifer Used for Compressed Air Energy Storage, G. C. Smith, L.E. Wiles, and W.V. Loscutoff, PNL-2546, February 1979.

- The Effects of Water on Compressed Air Energy Storage in Porous Rock Reservoirs, L.E. Wiles, PNL-2869, March 1979.

- Pacific Northwest Laboratory Annual Report for 1978 to the DOE Division of Energy Storage Systems - Compressed Air Energy Storage Technology Program, W. V. Loscutoff, PNL-2935, June 1979.

- Incremental Cost Analysis of Advanced Concept CAES Systems, C.A. Knutsen, Knutsen Research Services, PNL-3118, Seftember 1979.

- Numerical Analysis of Temperature and Flow Effects in a Dry, TwoDimensional, Porous-Media Reservoir Used for Compressed Air Energy Storage, L. E. Wiles, PNL-3047, October 1979.

- The Economics of Compressed Air Energy Storage Employing Thermal Energy Storage, S. C. Schulte and R. W. Rei17y, PNL-3191, November 1979. 
This document describes investigations performed to assess the structural behavior of porous rock compressed air energy storage (CAES) reservoirs subjected to loading conditions of temperature and pressure felt to be typical of such an operation. Analyses performed addressed not only the nominal or mean reservoir response but also the cyclic response due to charge/discharge operation.

The analyses were carried out by assuming various geometrical and material related parameters of a generic site. It should be emphasized that material properties of rock vary widely from site to site and even in different locations of a single site. Thus, results should be interpreted with this in mind.

The objective of this study was to determine the gross response of a generic porous reservoir. Thus, site specific details such as well casing placement techniques, bore hole size, and placement depth within the porous stratum were not explicitly addressed.

The site geometry for this study assumed a cylindrical model 122 $\mathrm{m}$ (400 ft) in diameter and $57 \mathrm{~m}$ (200 ft) high including thicknesses for the cap, porous, and base rock formations. The central portion of the porous zone was assumed to be at a depth of $518 \mathrm{~m}(1700 \mathrm{ft})$ and at an initial temperature of $20^{\circ} \mathrm{C}$. Cyclic loading conditions of compressed air consisted of pressure values in the range of 4.5 to $5.2 \mathrm{MPa}$ (650 to $750 \mathrm{psi})$, and temperature values between 143 and $204^{\circ} \mathrm{C}\left(290\right.$ and $\left.400^{\circ} \mathrm{F}\right)$. Air pressures in the porous zone showed little spatial variation, whereas substantial thermal gradients existed in the central portion of the model. Loading conditions at the central portion of the model indicate that thermal loading could be approximately twenty times larger than pressure loading. Thus, thermal structural effects were felt to be greater than those of pressure in causing rock stress levels.

Various modes of structural behavior were studied. These response modes were analyzed using loading conditions of temperature and pressure (in the porous zone) corresponding to various operational states during the first year of simulated site operation. 
The response characteristics included:

- Tensile stress level in the cap rock mass since this could conceivably allow leakage to occur.

- Fatigue stress magnitude in the cap rock and porous zone since cyclic loading will exist and is a potential reservoir damage mode.

- Porous rock stress level in relation to a Mohr Coulomb failure envelope for a Galesville sandstone.

Tensile stress levels in the cap rock were observed to occur towards the end of the one year simulation. The region affected was the top portion of the cap rock near the wellbore. This response was caused by two influences. The first influence was radial expansion of the hot central cap rock mass, moving radially and thereby inducing circumferential tensile stresses in the cooler surrounding rock. The other cause of cap rock tensile stress was initiated by vertical thermal growth of the central porous zone. This growth caused flexure of the cap rock to occur which resulted in tensile stresses on the top and compressive stress on the bottom of the cap rock layer. The magnitude of this flexure strain was found to be highly dependent on the degree of stiffness of the site overburden above the top surface of the cap rock.

Fatigue stress analysis was felt to be important due to the relatively large cyclic thermal component to which the porous zone would be subjected. Fatigue stresses in both the porous and cap rock regions were found to be concentrated in the vicinity of the wellbore. Fatigue stresses in the porous zone were found to be greater than the cap rock zone. In both regions it was further noticed that fatigue stresses during initial hot air injection tended to diminish and approach a steady state level as the operation continued during the one year simulation.

Nominal (noncyclic) stress levels in the porous zone were studied with reference to a Mohr Coulomb failure envelope developed from tests on Galesville sandstone. These tests were conducted especially for the CAES program. Attention was focused on utilizing confinement stress 
values and pore pressure values which were germane to CAES operation. Based upon these data and the assumptions of the modeling performed, it was found that the noncyclic stress levels in the porous zone were not sufficient to cause appreciable damage. In this context, it should be emphasized that the temperature at which the Mohr Coulomb data was generated deviated somewhat from nominal porous rock operating temperature. Comparison of stress level results to Mohr Coulomb data corresponding to more appropriate test conditions is underway.

The results of the structural analyses performed indicate that the most severely stressed region will likely be in the wellbore vicinity and hence highly dependent on the length of and placement technique utilized in the well production length. Analyses to address this specific area are currently being pursued. 
${ }^{\circ}$ 


\section{CONTENTS}

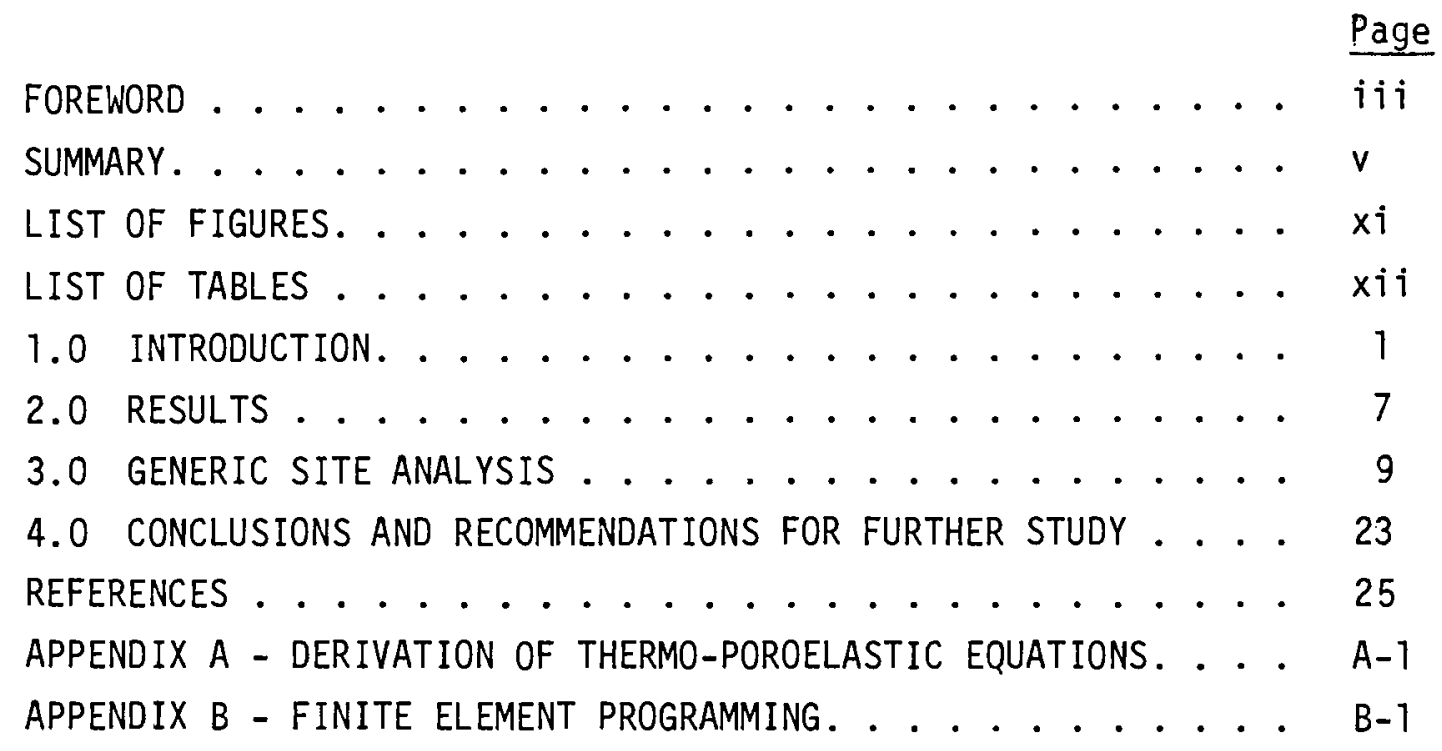




\section{FIGURES}

1. Cross Sectional View of a Porous Rock Compressed Air Energy Storage (CAES) Site. . . . . . . . . 2

2. Cross Section of a Typical Well ......... 3

3. Well Finite El ement Model ........... 10

4. Temperature Distribution at the End of Week $1\left({ }^{\circ} \mathrm{C}\right) \ldots \ldots 13$

5. Temperature Distribution at the End of Week $26\left({ }^{\circ} \mathrm{C}\right) \ldots 13$

6. Temperature Distribution at the End of Week $52\left({ }^{\circ} \mathrm{C}\right) \ldots 13$

7. Tensile Stress Distribution at the End of Week 1..... 16

8. Tensile Stress Distribution at the End of Week $26 \ldots \ldots$

9. Tensile Stress Distribution at the End of Week 52 . . . 16

10. Tensile Distribution at the End of Week 52 With Restrained Cap Rock..................... 16

11. Shear Stress Distribution at the End of Week 1...... 18

12. Shear Stress Distribution at the End of Week $26 \ldots 18$

13. Shear Stress Distribution at the End of Week 52 . . . 18

14. Mohr Coulomb Failure Envelope for Galesville Sandstone $\left(70^{\circ} \mathrm{C}\right) \ldots \ldots . . . . . . . . .19$

15. Mohr Coulomb Safety Factor Distribution at the End of Week 1.............. 20

16. Mohr Coulomb Safety Factor Distribution at the End of Week 26. . . . . . . . . . . . 20

17. Mohr Coulomb Safety Factor Distribution at the End of Week 52................ 20

18. Fatigue Shear Stress Levels at the Mid-Plane of the Cap Rock After One Year of Simulation .......... 21

19. Fatigue Shear Stress Levels at the Mid-Plane of the Porous Zone . . . . . . . . . . . . 2 21 
$\underline{\text { Page }}$

A.1 Differential Porous Element Illustrating Pore Pressure Loading in a (Macro) Stress Free Condition. . . . . . . A-3

B. 1 Coordinate Systems and Nodal Locations Used for Formulating Element Properties... . . . . . . . B-l

\section{TABLES}

1. Rock Properties ................. 14 
STRUCTURAL ANALYSIS OF POROUS ROCK RESERVOIRS SUBJECTED TO

CONDITIONS OF COMPRESSED AIR ENERGY STORAGE

\section{$1.0 \quad$ INTRODUCTION}

A compressed air energy storage (CAES) plant using a porous rock reservoir can best be described with reference to Figure 1 . The porous rock reservoir uses a large number of collection and distribution wells manifolded to the surface plant. Such a scheme will allow for large storage capacity. Flow losses will also be minimized due to low flow velocities. During daily or weekly periods of slack demand, excess generating capacity at an electric utility is utilized to compress air and store this air in an underground porous rock formation. During periods of peak demand, this air is withdrawn and utilized in a turbomachinery system to provide the required additional capacity. For conventional CAES plants, the air will be injected at relatively low temperatures. However, injection of air at higher temperatures is very important to eliminating the need for petroleum fuels by CAES plants. For this reason, PNL undertook studies of porous media subjected to hot air injection. This study examines mechanical and thermal stresses resulting from this condition.

Site location will be chosen where a relatively impermeable cap rock (possibly shale) forms a dome over a relatively permeable layer of porous sandstone. Since such a sandstone formation will most likely contain water, initial site development will require a preliminary charging period in which this water is displaced to the perimeter of the dome thus forming a sealed region of compressed air. Site operation will consist of cycling a fraction of this initial charge volume in accordance with the load requirements of the utility. 


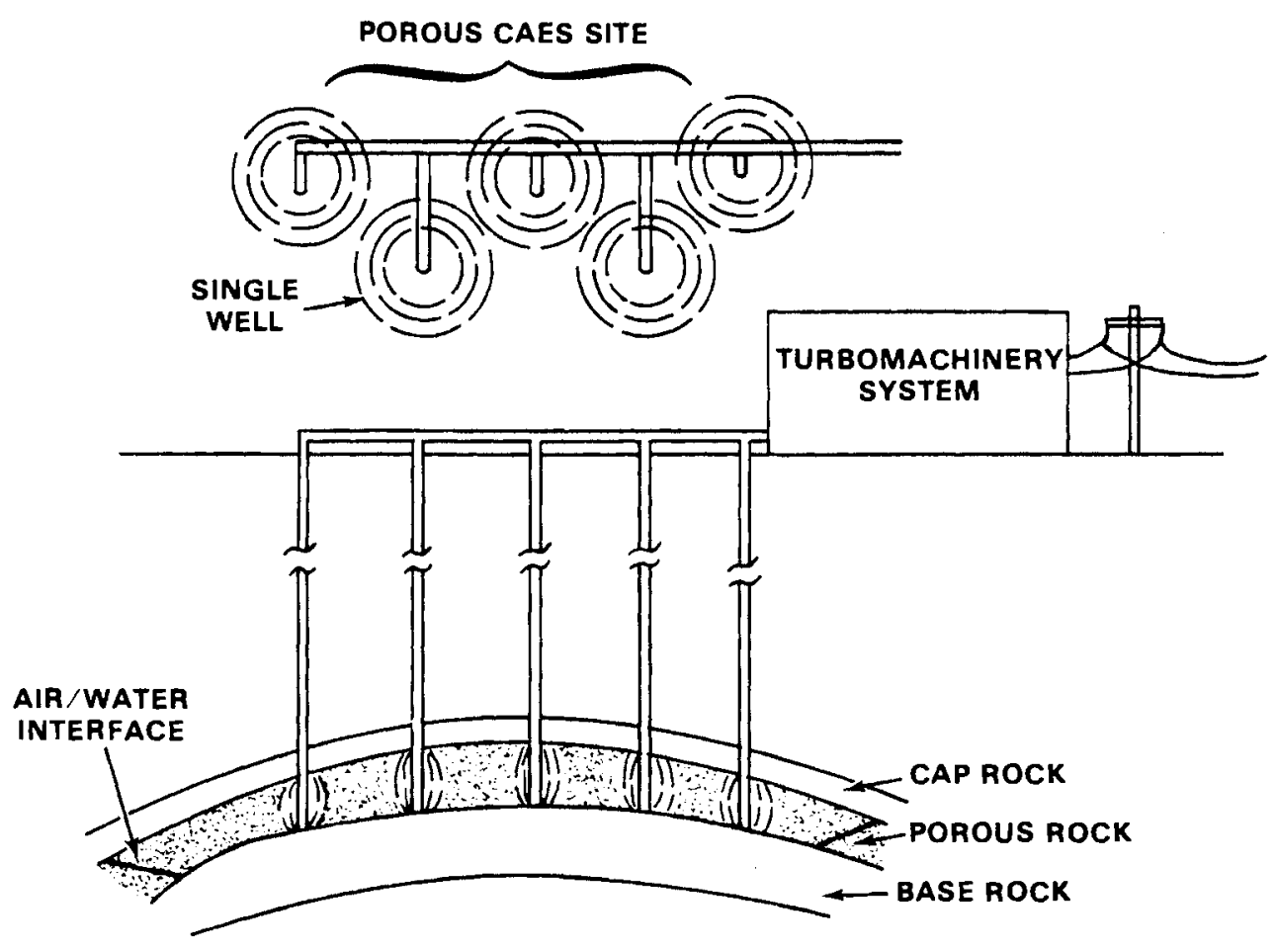

FIGURE 1. Cross Sectional View of a Porous Rock Compressed Air Energy Storage (CAES) Site.

The purpose of this report is to describe preliminary investigations conducted to address the structural response of the various rock masses subjected to CAES operation. Investigations of this sort are useful primarily for two reasons. These are:

- Porous rock damage could result in the production of sand particles which could in turn result in pore plugging or entrained particles and subsequent reduced site efficiency.

- Cap rock damage due to nominal or cyclic temperature and pressure loading could cause localized failure in the wellbore vicinity and thus allow air leakage.

The nature and origin of cap and porous rock stress levels can be described with reference to Figure 2. This figure depicts a single well in a porous CAES site. As hot compressed air is pumped down the well casing, 


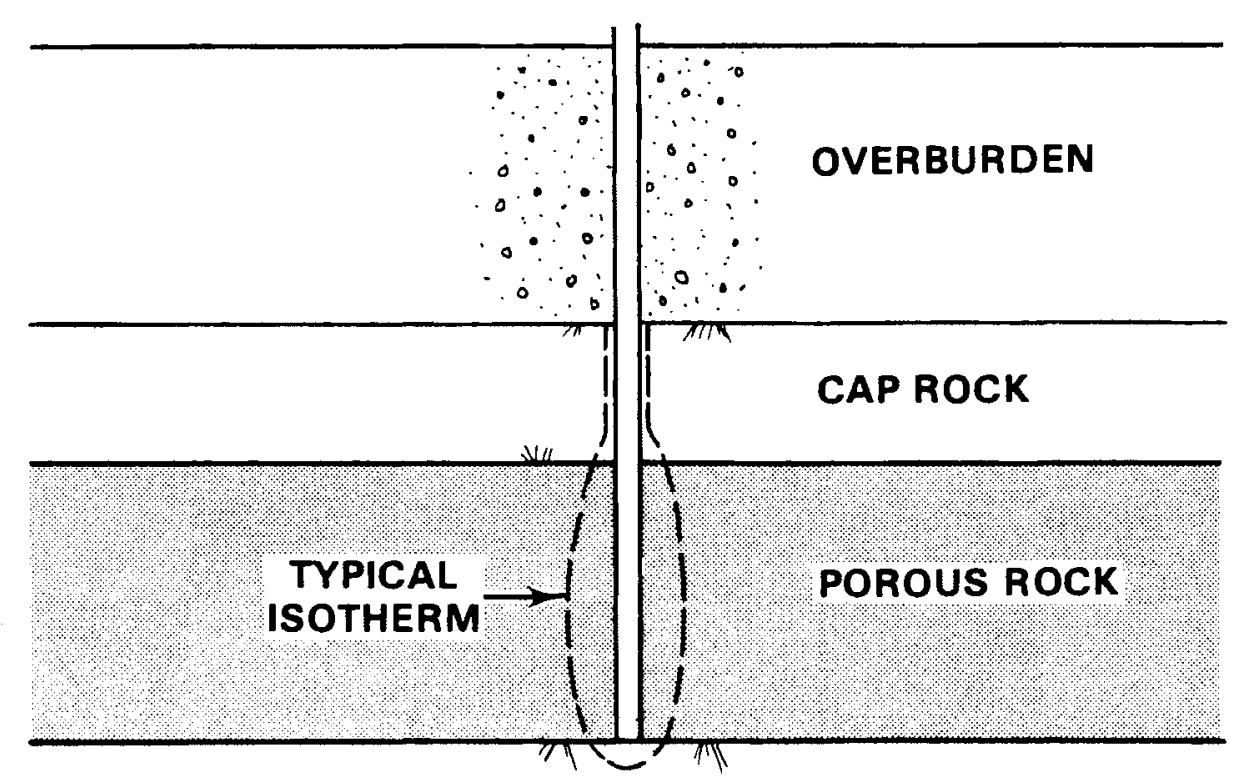

BASE ROCK

FIGURE 2. Cross Section of a Typical We11.

radial heat flow in the cap rock will cause radial thermal gradients to exist there. In the porous zone, the size of the thermally affected zone will be somewhat greater since thermal energy is transferred by flow as well as conduction in that region. The differences in the heat transport modes will tend to cause temperature distributions as illustrated in Figure 2 with temperature contour lines more closely spaced in the cap rock than in the porous zone.

Rock stresses will be caused by several influences in addition to nonuniform temperature distributions. Stresses resulting from thermal loading, however, will likely have the following characteristics.

- The hot inner portion of the cap rock will be compressive and will tend to induce tensile hoop or circumferential stresses in the cooler outer rock.

- Similar hoop and radial behavior will exist in the porous rock. 
- Vertical growth of the central porous zone will cause compressive vertical stresses in that region. In addition, this vertical growth will push against the cap rock and tend to induce flexure stresses (tensile on top and compressive on the bottom). The magnitude of this flexure, however, will depend largely on the stiffness of the overburden lying above the cap rock.

In addition to the thermal stress trends mentioned above, nominal site response will be influenced by stresses caused by pore pressure loading and stresses corresponding to in-situ conditions. Both of these stress trends will likely be compressive in nature. While pore pressure stress effects will be governed by operating conditions, in situ stresses will depend solely on site location and depth.

Vertical in situ stress components usually correspond closely that by overburden weight, but horizontal stress levels are much less predictable. These stresses are generally compressive in nature but may be greater or less in magnitude than the vertical stress at the same location.

Stress behavior trends discussed thus far have been concerned with nominal, noncyclic behavior. Fatigue stresses resulting from changing conditions of temperature and pressure of the stored air, however, could potentially be a significant rock damage mechanism.

During site charge/discharge operation, wellbore temperatures will cycle in temperature. This cycling will also affect the rock temperatures in the immediate vicinity of the wellbore. The penetration depth (radius away from the wellbore at which cycling occurs) will be small in the cap rock relative to the corresponding distance in the porous zone. This is due to the fact that thermal energy is transported by flow as well as conduction in the porous zone. As a result of this thermal response behavior, it can be anticipated that fatigue stresses due to thermal cycling will be greatest in the central portion of the production length and diminish with radius. 
Cyclic stresses due to pressure fluctuations will also contribute to the overall fatigue stress level. During charge and discharge of the porous zone, the radial pressure gradient will experience a direction change. The magnitude will depend on the permeability of the porous zone and the flow rates prescribed. Due to the radial nature of the flow, it can perhaps be anticipated that fatigue stresses due to pressure as well as thermal effects will be greatest near the wellbore. 



\subsection{RESULTS}

The elastic structural analysis of a single well indicated the following trends:

- Tensile stresses in the top portion of the cap rock away from the we11 center were observed. These stresses will likely cause some localized cracking of intact rock or some loosening of initially fractured rock.

- Tensile stresses were not found to exist in the portion of the model corresponding to the porous rock.

- A check of the porous rock stress level was made by using a Mohr Coulomb failure criteria for Galesville sandstone. Results showed that a factor of safety of about three existed for the simulated structural analysis. The Mohr Coulomb data was for temperature $\left(20^{\circ} \mathrm{C}\right)$ substantially different from the nominal operating temperature, however.

- Rock fatigue stress levels were found to be concentrated in the vicinity of the wellbore. This was especially true of the cap rock fatigue levels. This fatigue stress result should be considered in a qualitative sense only, however, since the actual wellbore and casing were not modeled.

The actual significance of the response modes depends on rock properties endemic to an actual site. A host of candidate rock types is currently being tested to aid in this interpretation. 


\subsection{GENERIC SITE ANALYSIS}

Quantitative structural response was investigated by performing a series of analytical investigations. Since site wells are expected to be separated a considerable distance, structural analysis treated only a single well. As significant stresses are expected to be concentrated in the central region of the well, it is anticipated that the effects of this assumption are minimal.

The analysis technique used in performing these investigations was the finite element method (Zienkiewicz, 1977). The finite element method was employed by making use of a modified version of the ADINA computer program. This program is described in brief detail in Appendix $B$.

The main modifications made to this program involved those required to treat the effects of pore pressure in the porous zone of the well. The technique used is known as poroelasticity (Lubinski, 1954; Stagg and Zienkiewicz, 1968; Mordgren, 1977). Derivations and a discussion dealing with this concept are included in Appendix $A$.

The geometry of the well model used in these investigations is illustrated in the finite element mesh configuration shown in Figure 3. The model is axisymmetric, and the top surface of the cap rock is assumed to be 491 meters $(1612 \mathrm{ft})$ deep. The model radius $(200 \mathrm{ft})$ was chosen so that response in the central portion of the model would behave in a manner similar to a model of much larger radius. Far field effects are felt to be adequately treated by a model of $200 \mathrm{ft}$ radius.

The model shown in Figure 3 contains a total of 270 parabolic isoparametric elements and possesses 1892 degrees of freedom. The accuracy of this element (which utilizes midside nodes deleted in Figure 3 for the sake of clarity) is well illustrated in the literature (Zienkiewicz, 1977). 


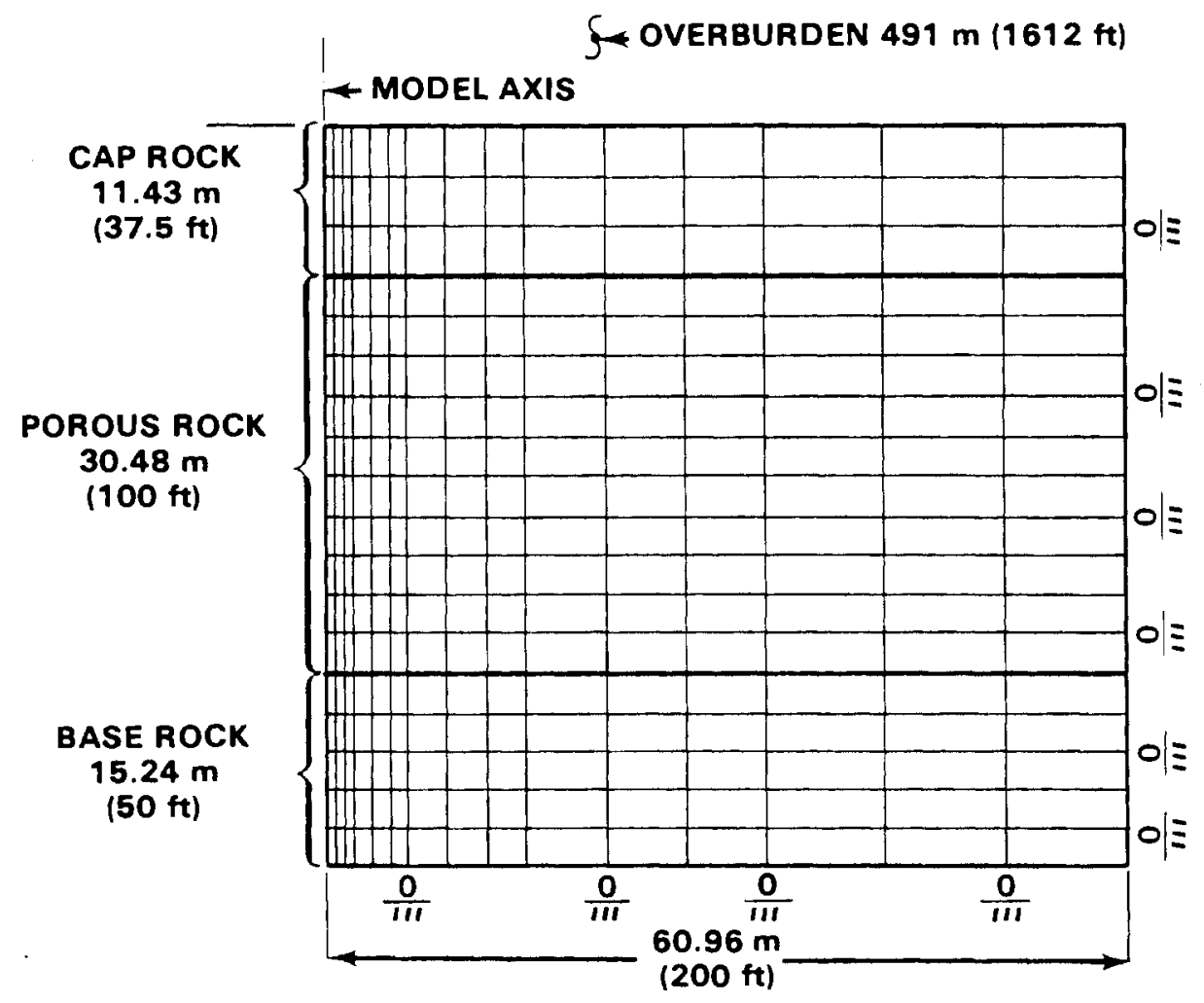

FIGURE 3. Well Finite Element Model.

The objective of this effort was to study gross reservoir response to applied loading. Determination of localized stresses which are dependent on wel1 casing size, termination technique, and placement method used was not included in these initial analyses. For this reason, well casing material was neglected and the central portion of the well was assumed to be solid. The significance of this assumption on the localized stresses in the central portion of the well will depend largely on the well completion technique utilized. If the casing is not in stiff contact with the porous rock, then radial confinement stress at the rock/casing interface will not exist. This in turn will tend to increase the shear stress level in that zone. If the casing is grouted to the porous rock with only intermittent perforations, then the effects of the assumption dealing with neglect of the well casing are likely to be less severe. In particular, if the thickness to radius ratio of 
the casing is nearly the same as the Young's modulus ratio of the porous rock to steel, then localized radial stiffness of the model should closely approximate structural behavior of rock adjacent to a grouted casing.

Stress levels in the various rock masses will have components caused by the following effects:

- in situ conditions

- stresses caused by nonuniform temperatures

- stresses caused by pore pressure loading

These loading conditions will now be described in sequence.

In situ stresses are those stresses existing in the rock before wel1 development. These stresses vary greatly not only with depth but also with site location. Typical methods for characterizing in situ stresses involve a parameter representing the ratio of the mean horizontal stress to the vertical stress. Mean horizontal stress is a convenience for axisymmetric analysis. Bore hole testing for various locations has revealed that this ratio may be less than or greater than unity (Jaegar and Cook, 1976). Vertical stresses, however, are much more predictable. Results show that vertical stresses are very nearly equal to the overburden weight. Geologic densities are such that a factor of 1 psi per foot of depth is a typical value for vertical in situ stress. For this reason, the vertical in situ stress level in the model shown in Figure 3 was initially simulated by applying a vertical load of $11.1 \mathrm{MPa}$ (1612 psi) to the top surface of the cap rock.

Horizontal in situ stress levels were simulated by using radial restraints at the outer perimeter of the model. The Poisson effect will thus cause a horizontal stress of about one third of the vertical stress. While experimental observations show values both greater than and less than one third for this ratio, most results are usually greater. Thus, while the current model only represents a generic site, it can be anticipated that compressive horizontal stresses in many sites would be somewhat greater than those predicted here. Put another way, tensile 
stresses due to combined loading effects in the generic model can be expected to be greater (in a probabilistic sense) than an actual site. Thus, the model should conservatively predict rock damage due to tensile cracking.

Thermal loading due to nonuniform heating of the rock masses adjacent to the well is another source of structural loading. The temperature and pressure data used in analyses performed were taken from another investigation. Techniques and assumptions utilized in determining this data are given in a paper by Wiles (1979).

The design life of a compressed air energy storage site is expected to be approximately thirty years. While it can be anticipated that thermal response will change somewhat during the later years of site operation, most likely these changes will tend to diminish with site age. An independent temperature and pressure simulation described in a paper by wiles (1979) was performed prior to any structural investigations. Results of that investigation indicated that during the first year of simulated operation, very little change in thermal or pressure response modes occurred after about six months. Because of this, structural investigations were only performed for loading conditions corresponding to the first year of simulated site operation.

Temperature and pressure from for the simulation performed by Wiles (1979) had the following ranges at the central portion of the well during a daily cycle:

- temperature $143-204^{\circ} \mathrm{C}$

- pressure $4.5-5.2 \mathrm{MPa}$

Structural analyses were performed at the ends of weeks 1, 26, and 52 . Temperature contour plots corresponding to this data are shown in Figures 4, 5, and 6, respectively. Pressure response of the reservoir was much more uniform than the thermal response. Pressure nonuniformities in the porous zone varied only several psi from pressure corresponding to wellbore values. 

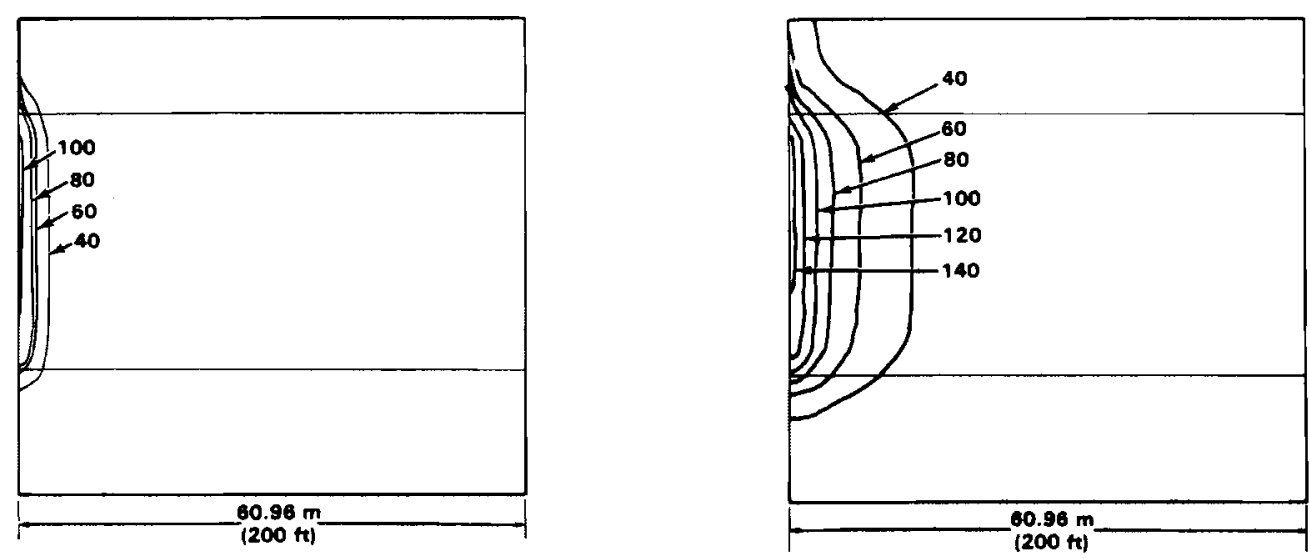

FIGURE 4. Temperature Distribution FIGURE 5. Temperature Distribution at the End of Week $1\left({ }^{\circ} \mathrm{C}\right) \longrightarrow$ at the End of Week $26\left({ }^{\circ} \mathrm{C}\right)$

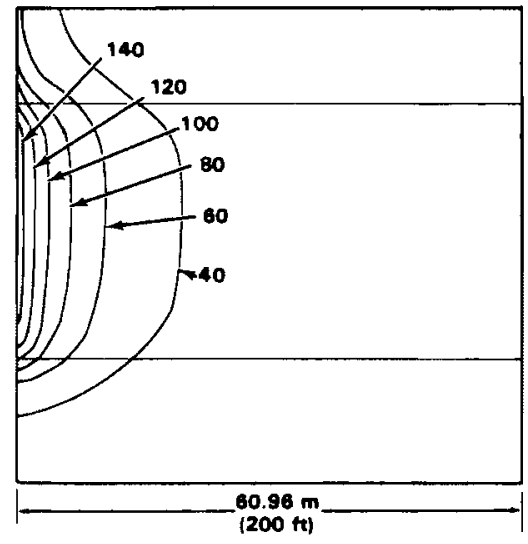

FIGURE 6. Temperature Distribution at the End of Week $52\left({ }^{\circ} \mathrm{C}\right)$ 
The growth of the thermal effects in the various rock masses can be seen in Figures 5 through 6 . The size of the thermally affected zone in the porous rock is appreciably greater than in the cap or base rock zones. This is caused by the additional heat transport due to fluid flow in the porous zone.

Stresses induced by thermal effects can be both tensile and compressive. During initial stages of site development, hot regions adjacent to the wellbore locations will tend to expand and thereby be mainly compressive. Cooler outer regions will in turn be stretched circumferentially and. incur some tensile stresses due to thermal effects. This type of behavior can be anticipated in both the porous and cap rock regions.

In addition to this tensile and compressive hoop behavior, vertical expansion of the porous zone will likely induce flexure strain on the cap rock. This effect will likely increase when the diameter of the thermally affected zone matures. In addition to the size of the thermal influence in the porous zone, the stiffness of the cap rock and the overburden will influence this flexure behavior. Initially, however, overburden stiffness was neglected.

The finite element model shown in Figure 3 was used with material properties given in Table 1 and temperature/pressure data mentioned previously to conduct a number of analyses. The results of these analyses will now be given.

TABLE 1. Rock Properties

\begin{tabular}{|c|c|c|c|}
\hline & $\begin{array}{l}\text { Porous } \\
\text { Rock }\end{array}$ & $\begin{array}{l}\text { Caprōck and } \\
\text { Base Rock }\end{array}$ & \\
\hline$(\mathrm{MPa})$ & $3.0 \times 10^{4}$ & $3.2 \times 10^{4}$ & CRC Handbook, 1973 \\
\hline & .25 & .25 & CRC Handbook, 1973 \\
\hline$\left({ }^{\circ} \mathrm{C}^{-1}\right)$ & $10^{-5}$ & $10^{-5}$ & CRC Handbook, 1973 \\
\hline & .20 & -- & Assumed \\
\hline & .25 & -- & Assumed \\
\hline
\end{tabular}


Tensile stresses for the three load cases (temperature and pressure load data from weeks 1, 26, and 52) are shown in Figures 7, 8, and 9. These are maximum principal stresses. In most cases, it was observed that the maximum tensile stress occurred in the "hoop" direction, i.e., out of the paper. As can be seen from Figure 7, the size of the zone in the cap rock exhibiting tensile behavior is quite small. These stresses are attributed to the effect mentioned previously of the hotter inner rock stretching the cooler outer rock.

The tensile stress trends increase somewhat for load cases corresponding to weeks 26 and 52 (Figures 8 and 9). In stress results from these two cases, the thermal growth of the thermally active porous zone (see Figures 5 and 6) can be seen. Vertical force caused by upward expansion of the central porous region is inducing a tensile component of flexure stress on the upper surface of the cap rock. This flexure combined with a compressive field caused by local heating at the central portion of the model apparently causes a partial toroidal region of tensile stress affected rock.

Cap rock flexure seems to be a major behavioral mode contributing to tensile stress. Overburden stiffness will influence this flexure for a given thermal distribution. For this reason, a sensitivity analysis was performed in an attempt to bound this influence. The analyses presented thus far, includes overburden loading but neglects overburden stiffness.

The analysis to be described now assumes the overburden to be infinitely stiff (rigid) in the vertical direction. This analysis was performed by applying vertical restraints at nodes along the top surface of the cap rock (see Figure 3 ). Free radial motion, however, was allowed. In situ stress effects were applied so as to simulate the same stress level as the previous overburden condition. Tensile stresses for this condition corresponding to one year loading conditions are shown in Figure 10. A substantial reduction in the maximum tensile stress 1.0 $\mathrm{MPa}$ versus $6.0 \mathrm{MPa}$ ) can be seen. Vertical variation in tensile stress is still present in Figure 10. Since flexure strain is prevented, this 


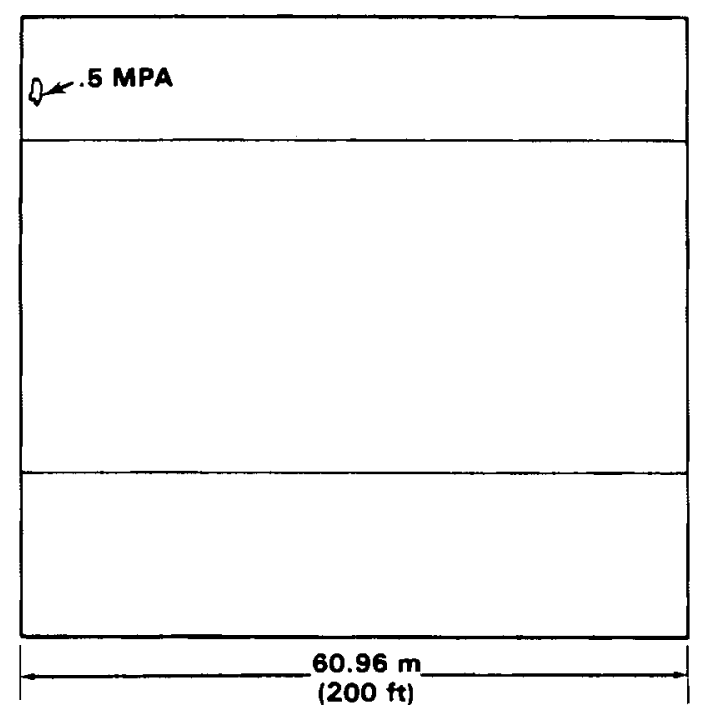

FIGURE 7. Tensile Stress Distribution at the End of Week 1.

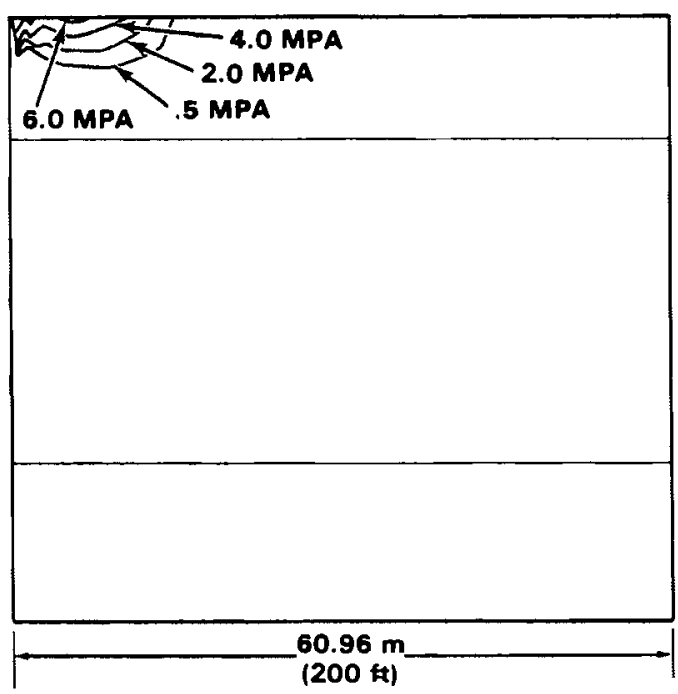

FIGURE 9. Tensile Stress Distribution at the End of Week 52.

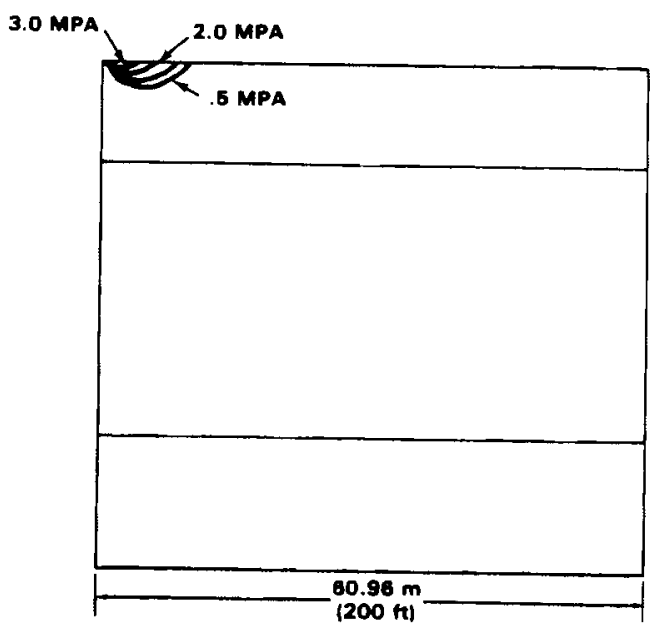

FIGURE 8. Tensile Stress Distribution at the End of Week 26.

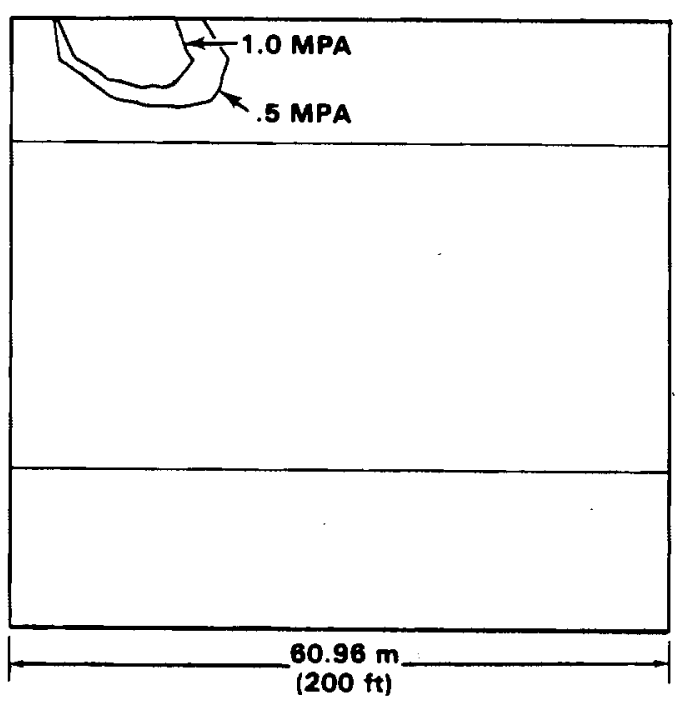

FIGURE 10. Tensile Distribution at the End of Week 52 With Restrained Cap Rock. 
must be due to vertical thermal gradients in the cap rock. The lower hot regions of the cap rock are expanding and stretching the cooler upper region.

Tensile stresses in the porous zone were not observed for either sets of analyses corresponding to the different overburden treatments. While radial temperature gradients will perhaps cause a tensile thermal stress component in the porous zone, in situ and pore pressure effects seem to be of sufficient magnitude to cancel this thermally induced tensile behavior.

Another stress parameter investigated was maximum shear stress. This stress level was determined by computing the three principal stresses of each element nodal point and taking half of the maximum principal stress difference. Contour plots of this stress parameter are shown in Figures 11 through 13 for the three sets of loads considered. These plots correspond to the set of analyses utilizing no overburden stiffness, i.e., only overburden pressure to produce in situ effects. Shear stress results with "constrained" overburden were observed to be very similar, however.

A failure criteria often applied to rock like materials is the Mohr Coulomb criteria (Stagg and Zienkiewicz, 1968; Jaegar and Cook, 1976). This failure criteria is in terms of shear as well as normal stresses. The failure envelope used for this comparison is shown in Figure 14. Data corresponding to this failure envelope was taken specifically for the CAES program using Galesville sandstone test specimens and is reported in detail by Blacic (1979).

The Mohr Coulomb failure envelope is essentially a line on a Mohr's circle plot separating failure and nonfailure stress conditions. In Figure 14, points representing stress states above the envelope correspond to failure. Points below the envelope correspond to nonfailure. For nonporous rock, the abscissa is simply normal stress. For porous rock, however, it has been observed experimentally that an effective normal stress $(\sigma-P)$ as shown in Figure 14, is the crucial parameter (Stagg and Zienkiewicz, 1968). 


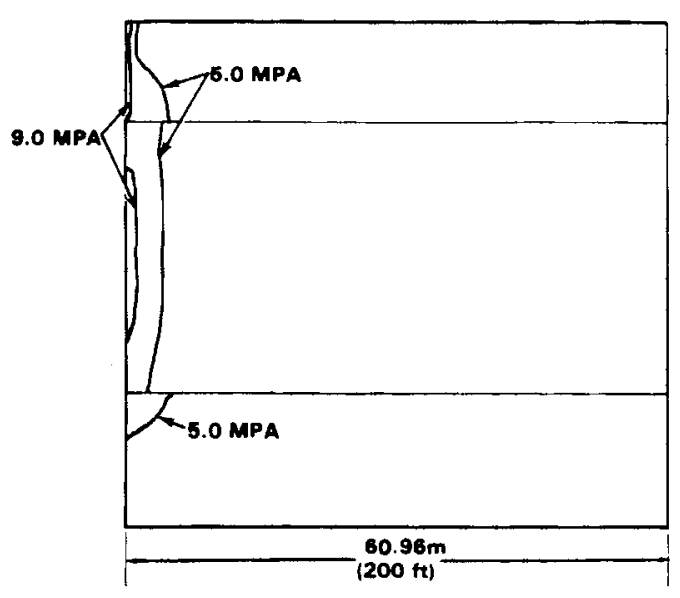

FIGURE 11. Shear Stress Distribubution at the End of Week 1

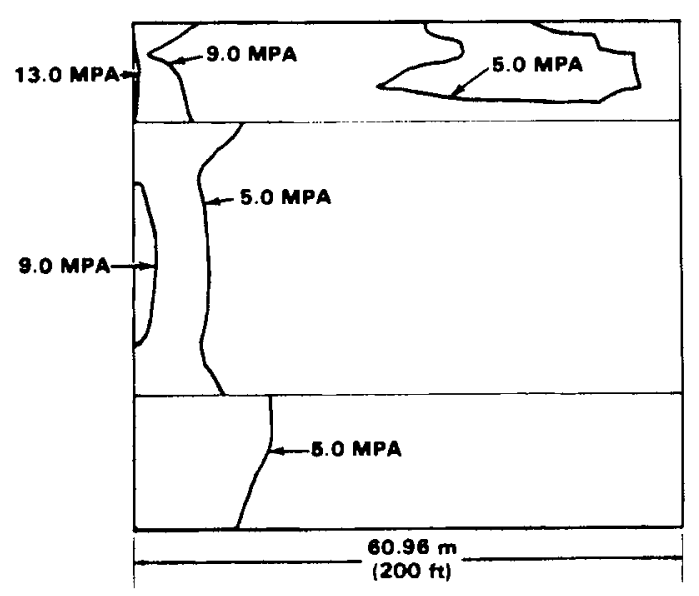

FIGURE 12. Shear Stress Distribubution at the End of Week 26

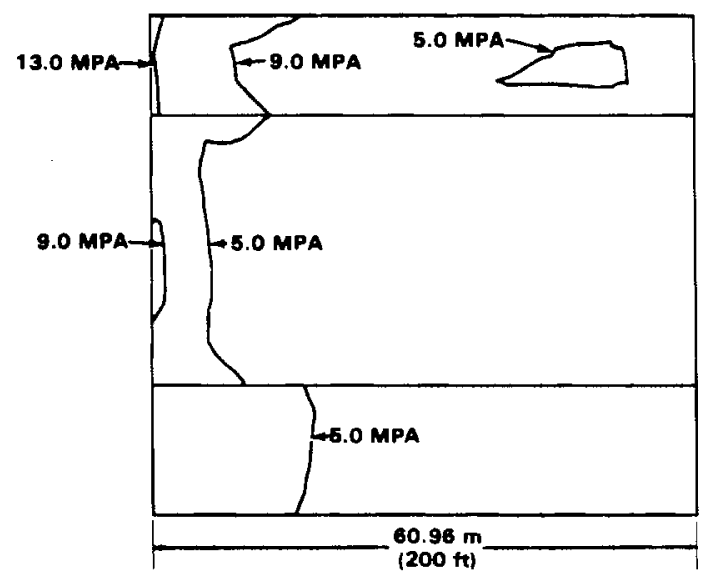

FIGURE 13. Shear Stress Distribution at the End of Week 52 


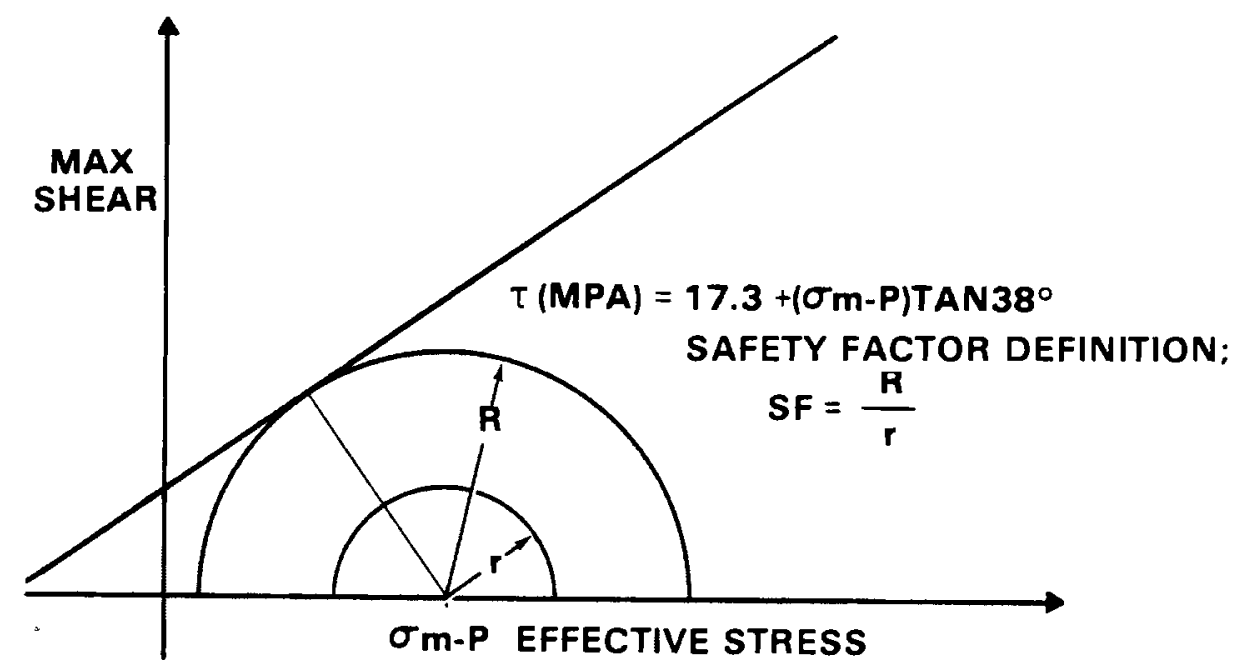

FIGURE 14. Mohr Coulomb Failure Envelope for Galesville Sandstone $\left(20^{\circ} \mathrm{C}\right)$

Stress for a point in the porous zone corresponds to a set of Mohr's circles on Figure 14. The enveloping three-dimensional Mohr's circle bounds (in $\sigma, \tau$ space) all stress states for all directions at the point in question. A measure of how close the stress at a point comes to satisfying the failure criteria is the ratio $R / r$ where $r$ is the radius of Mohr's circle at the point in question, and $R$ is the radius of the concentric circle which is tangent to the failure envelope. A safety factor less than unity signifies failure while one greater than unity signifies no failure.

Values of the safety factor defined in this fashion were contour plotted and are included as Figures 15, 16 and 17 for loading conditions corresponding to the ends of weeks 1,26 , and 52 , respectively. As can be seen from these plots, the zone most severely stressed is in the central region of the model. According to the values shown, the minimum safety factor is about three; thus, no failure is predicted. In this regard, two assumptions should be acknowledged.

- The Mohr Coulomb data was taken at ambient $\left(20^{\circ} \mathrm{C}\right)$ temperature.

- Localized well borehole stresses were not treated in the model. 


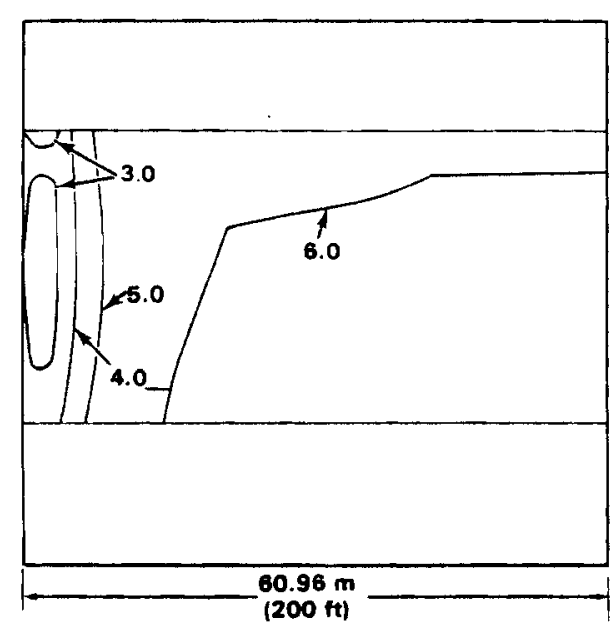

FIGURE 15. Mohr Coulomb Safety Factor Distribution at the End of Week 1

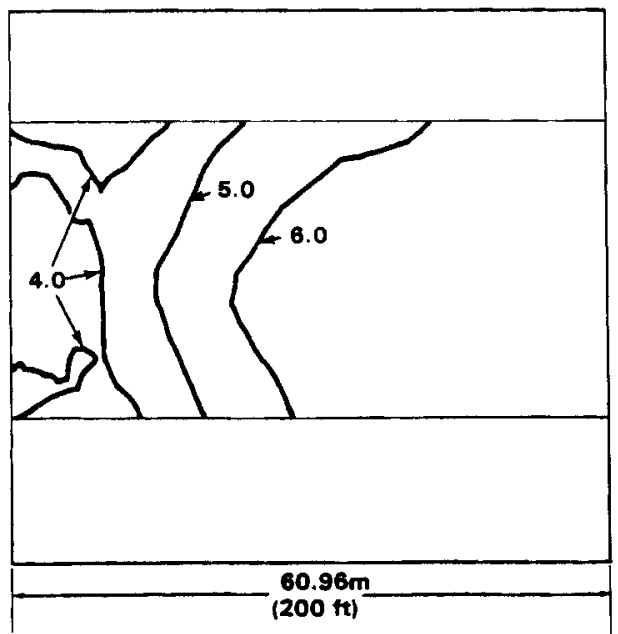

FIGURE 16. Mohr Coulomb Safety Factor Distribution at the End of Week 26

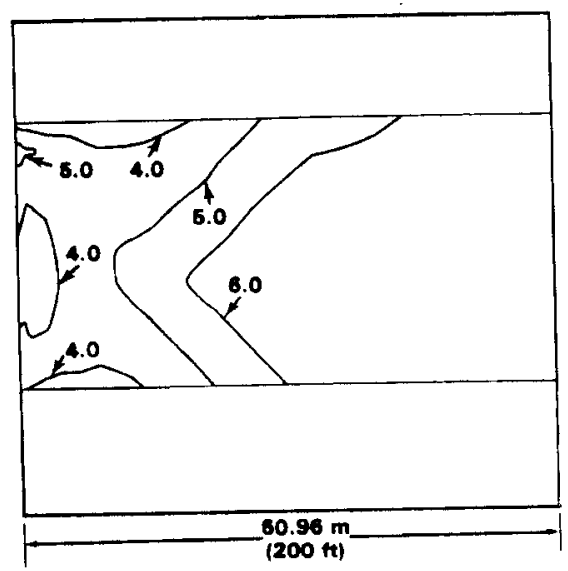

FIGURE 17. Mohr Coulomb Safety

Factor Distribution

at the End of Week 52. 
Analyses are currently being pursued which examine the validity of these two assumptions.

Stress levels discussed thus far (max tensile, max shear, and Mohr Coulomb levels) are associated with the nominal, noncyclic, rock behavior. Since the reservoir is subjected to cyclic operation, it is felt that a potentially significant damage mode could be cyclic stress levels incurred either by the weekly or daily component of structural load variation.

Rock damage due to fatigue (cyclic) stress variations will tend to depend not only on the magnitude of stress variation but also on the number of cyclic variations the reservoir incurs. Since there are five times as many daily cycles as weekly cycles, cyclic variation in stresses was evaluated only for the daily cycling level. This was done by "loading" the model of Figure 3 with temperature/pressure differences incurred over the last 12 hours of weeks 1,26, and 52 . The stresses incurred due to this load difference thus represent the cyclic stress caused by load variation. In situ effects have no cyclic component, of course.

Fatigue stresses analyzed in this fashion were used to compute fatigue shear stress levels. Stresses are shown in Figures 18 and 19

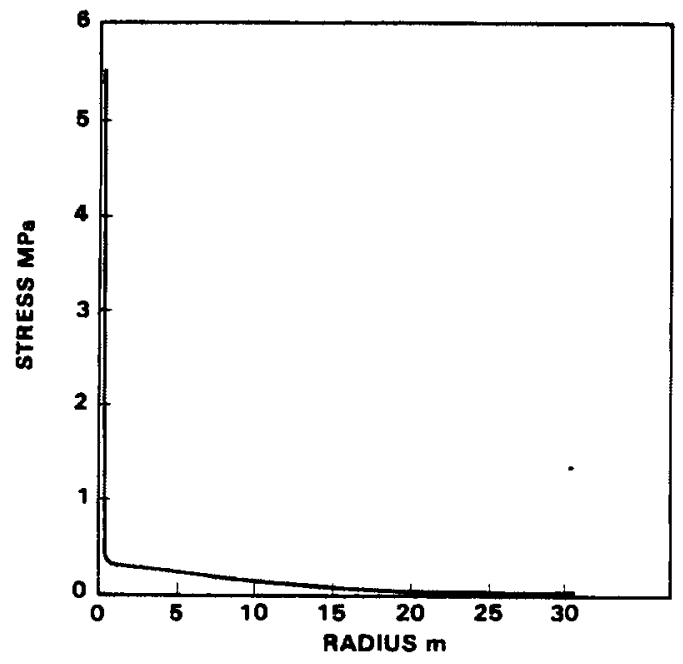

FIGURE 18. Fatigue Shear Stress Levels at the Mid-Plane of the Cap Rock After One Year of Simulation

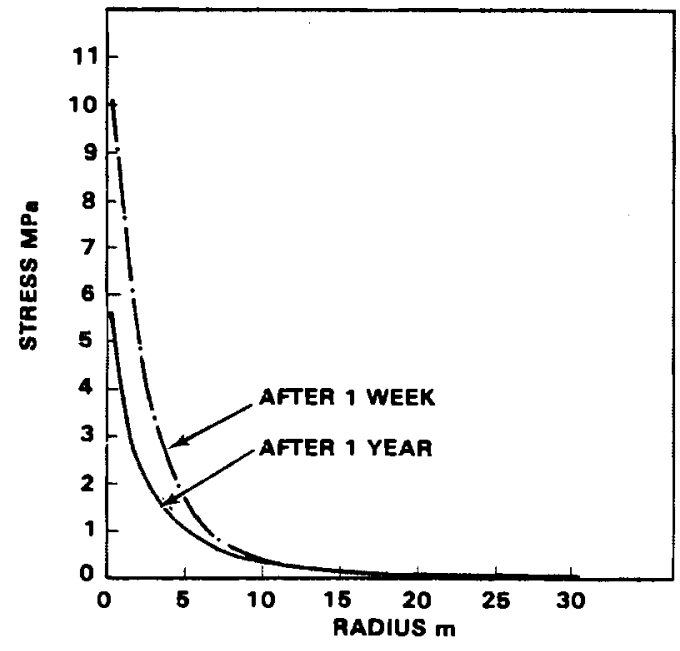

FIGURE 19. Fatigue Shear Stress Levels at the Mid-Plane of the Porous Zone 
representing the distributions in the mid-planes of both the cap and porous rock regions. As can be seen from these two figures, fatigue structural effects are concentrated in the central region of the well. Cyclic variations in the cap rock stress level were nearly independent of well age. Thus, only those corresponding the "year end" data were plotted. In the porous zone, some variation in fatigue stress with reservoir age was noticed. The distribution for the data at mid-year (week 26) was not plotted. It was very close to the year end results, however. This leads one to suspect that the steady-state fatigue shear stress distribution resulting from long term operation will be similar to the corresponding values at the end of one year. 


\subsection{CONCLUSIONS AND RECOMMENDATIONS FOR FURTHER STUDY}

The stress levels shown in this report should be interpreted with due consideration given to the assumptions made in carrying out the analyses. The regions of the model which indicated the most severe stress condition were concentrated in the central wellbore vicinity. In this context, several assumptions made in carrying out the structural analysis will no doubt have substantial influence on these stress levels. In particular, the following site dependent and well casing dependent features will no doubt have significant influences.

- the size and thickness of the casing

- the locations along the casing which are grouted into place

- the degree of fracturing produced by the well drilling

- the casing termination level in the porous zone

Plans are underway to address some of these localized features.

The degree of structural communication of the well casing with the porous rock will influence the radial stress level in that region. If no radial support is provided, between the casing and the rock, then this diminished degree of confinement will likely increase the shear stress levels in that region. If the casing does provide radial confinement, this affect will be diminished. In particular, if the radius to thickness ratio of a tight fitting casing is approximately equal to the Young's modulus ratio of steel to porous rock, then the effects of neglecting the casing from a purely elastic model will be minimal.

While some of the results presented in this report are highly dependent on localized wellbore features, certain structural trends are felt to be somewhat independent of this. Tensile stress is one behavioral mode which probably falls into this category. The gross thermal response 
is such that localized hot regions in the central part of the well will likely experience compressive stresses. Tensile behavior, if occurring at al1, will most likely occur in the region of cap rock removed from the wellbore and from the porous media/cap rock interface. 


\section{REFERENCES}

K. J. Bathe, Adina - A Finite Element Program for Automatic Dynamic Incremental Nonlinear Analysis, MIT Report 82448-1, 1976.

K. J. Bathe, Static and Dynamic Geometric and Material Nonl inear Analys is Using Adina, MIT Report 82248-2, 1977.

J. D. Blacic, "Cyclic Thermo Mechanical Properties of Galesville Sandstone", Proceedings of the 1979 Mechanical and Magnetic Energy Storage Contractor's Review Meeting, Washington, D.C., 1979.

R. D. Cook, Concepts and Applications of Finite Element Analysis, John Wiley and Sons, 1974 .

CRC Handbook for Applied Engineering Science, 2nd Edition, CRC Press, Cleveland, $\mathrm{OH}, \mathrm{T} 973$.

J. C. Jaegar and G. W. Cook, Fundamentals of Rock Mechanics, 2nd Edition, John Wiley and Sons, New York, 1976.

H. L. Langhaar, Energy Methods in Applied Mechanics, John Wiley and Sons, Inc., New York, 1962.

A. Lubinski, "The Theory of Elasticity for Porous Bodies Displaying a Strong Pore Structure", Proceedings of the Second U.S. Congress of Applied Mechanics, 1954.

R. P. Mordgren, "Strength of Well Completions", Eighteenth Symposium on Rock Mechanics, Johnson Publishing Co., Boulder, CO, 1977.

K. G. Stagg and 0. C. Zienkiewicz, Rock Mechanics in Engineering Practice, John Wiley and Sons, New York, 1968.

L. E. Wiles, Numerical Analysis of Temperature and Flow Effects in a Dry, Two-Dimensional Porous Media Used for Compressed Air Energy Storage. PNL-3047, Pacific Northwest Laboratory, Richtand, WA, 1979.

0. C. Zienkiewicz, The Finite Element Method, 3rd Edition, McGraw-Hill Book Co., New York, NY, 1977. 
APPENDIX A

Derivation of Thermo-Poroelastic Equations

In this appendix, a derivation of poro-elastic principals is presented. Here it will be shown that (with one slight exception) elastic treatment of an elastic porous medium with pore pressure effects and thermal effects is equivalent to an initial strain problem such as a thermoelastic formulation, a formulation involving swe11, or any other "initial strain" quantity. This will be done by making use of variational principles. Once this variational equivalence is shown, then solution techniques (in particular the finite element method) applicable to more common initial strain problems such as thermoelastic problems can be immediately applied for the purpose of obtaining numerical solutions. Discussions relating to poroelastic formulations along lines other than variational principles are given by Lubinski (1954), Stagg (1968), and Mordgren (1977).

The following notation will be employed:

P pore pressure

E Young's modulus (dry) of the porous medium

$\checkmark$ Poisson's ratio

$B$ macro bulk modulus $E / 3(1-2 v)$ of the porous material

${ }_{C}$ micro bulk modulus of the interpore material

$B \quad B / B_{C}$

$\tilde{\sigma}$ macro stress $\left[\begin{array}{llllll}\sigma_{x} & \sigma_{y} & \sigma_{z} & \sigma_{x y} & \sigma_{x z} & \sigma_{y z}\end{array}\right]$ in vector form

$\pi \quad$ potential energy

$U$ strain energy density

$\tilde{F}$ surface traction vector

$\tilde{v}$ displacement vector $(u, v, w)$ represent cartesian $(x, y, z)$ components

$\varepsilon_{0} \quad$ scaler initial strain term

$\tilde{\varepsilon}_{0} \quad$ initial strain vector

$\tilde{\varepsilon} \quad$ total strain vector

$f$ volume porosity of the porous material

$$
f=\frac{\text { microscopic void volume }}{\text { macro volume }}
$$

$\bar{D} \quad$ elasticity matrix 
The porous material is assumed to be elastic and isotropic.

In formulating the elastic principles of a porous continuum, the precise meaning of stress is essential. Stress as used in this report will be discussed with reference to Figure A.1. For a unit porous cube of porosity $f$, the pore fracture surface area on a side is $f$ and the surface area fraction composed of solid material is 1-f. Macroscopic normal stress shall be defined as the net force on the solid portion of a face divided by the area of that differential face. Thus for a macro normal stress of $\sigma$ represents a mean micro stress of $\sigma / 1-f$. The localized value of micro stress is not specifically addressed and would depend on micro elastic characteristics of the porous material. This definition of macro stress assumes that the differential cube is large relative to the pore size.

The task now at hand is to derive an expression for the initial strain of a differential porous element subjected to the combined effects of pore pressure and temperature. The term initial strain used in this context implies macro stress free strain.

The initial strain component due to temperature is just $\alpha$ There $\alpha$ is the macro coefficient of thermal expansion and $T$ is the temperature increase from a reference temperature at which the zero strain condition is assumed.

The initial strain contribution due to pore pressure is not quite so straight forward. Assume that the porous differential element is totally immersed in a pressurizing fluid. The micro stress acting on the solid material is $-P$ (minus signifying compression). The macro stress on the other hand is $-P(1-f)$. Every portion of the material will now have a microscopic stress of $-P$. The volumetric strain will be $-P / B_{C}$ where $B_{C}$ is the bulk modulus of the porous constituent. Linear strain will be $-P / 3 B_{C}$. In order to make the element stress free, normal macro tensile stress of magnitude $P(1-f)$ must be applied. This will give a volumetric and linear strain contribution of $P(1-f) / B$ and $P(1-f) / 3 B$, 


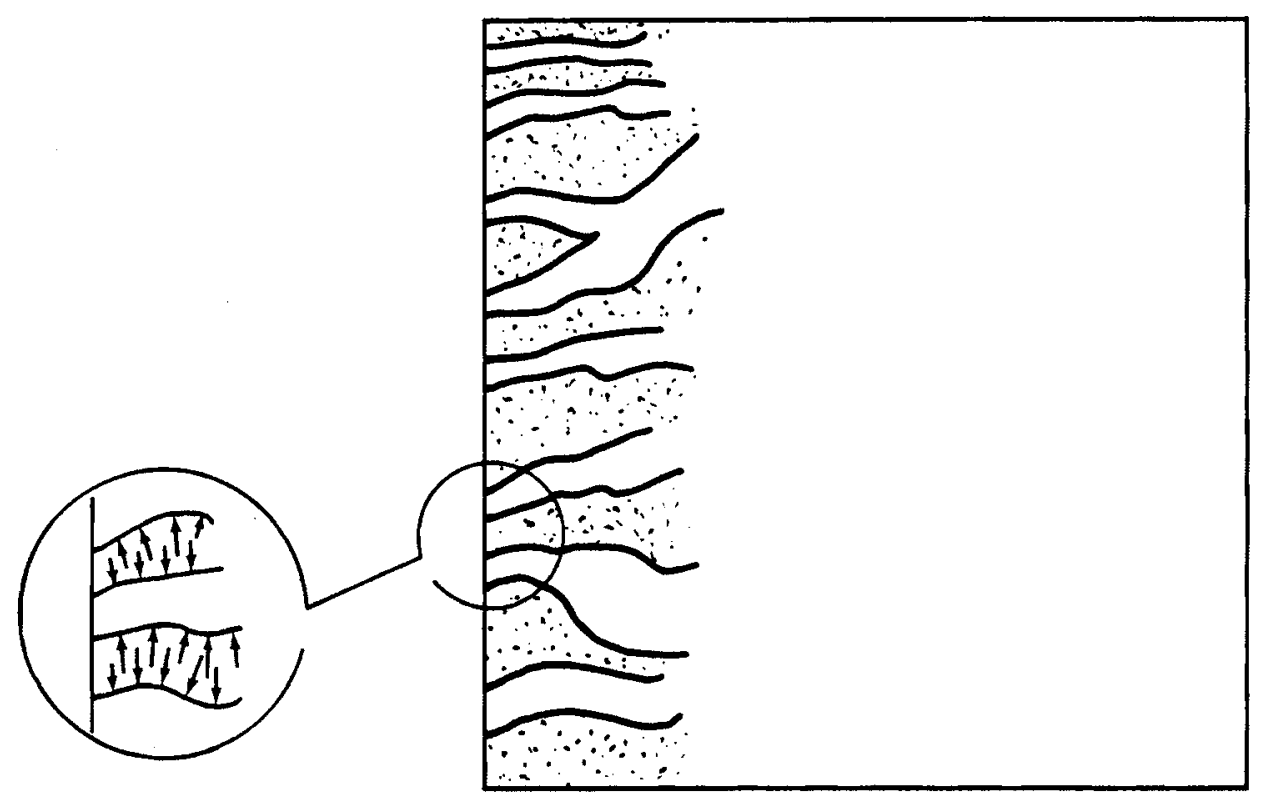

FIGURE A.1 Differential Porous Element Illustrating Pore Pressure Loading in a (Macro) Stress Free Condition.

respectively where $B$ is the macroscopic bulk modulus. The initial strain considering thermal and pore pressure influences is thus:

$$
\varepsilon_{0}=\frac{-P}{3 B_{C}}+\frac{P(1-f)}{3 B}+\alpha T
$$

Defining $B$ as $B / B_{C}$ and recognizing that $B=E / 3(1-2 v)$, the initial strain expression becomes:

$$
\varepsilon_{0}=P \frac{(1-2 v)}{E}(1-\beta)+\alpha T-P f \frac{(1-2 v)}{E}
$$

It should be mentioned that the conditions under which the initial strain, stress free, state will occur is somewhat of an analytical artifice. As can be seen in Figure A.1. Pressure does not act normal to the face 
of the porous differential element at the pore face. Thus, the pressure must be thought of as being conceptually applied rather than applied by a. transferring fluid.

The stress strain relations for an initial strain elastic formulation in cartesian coordinates takes the form

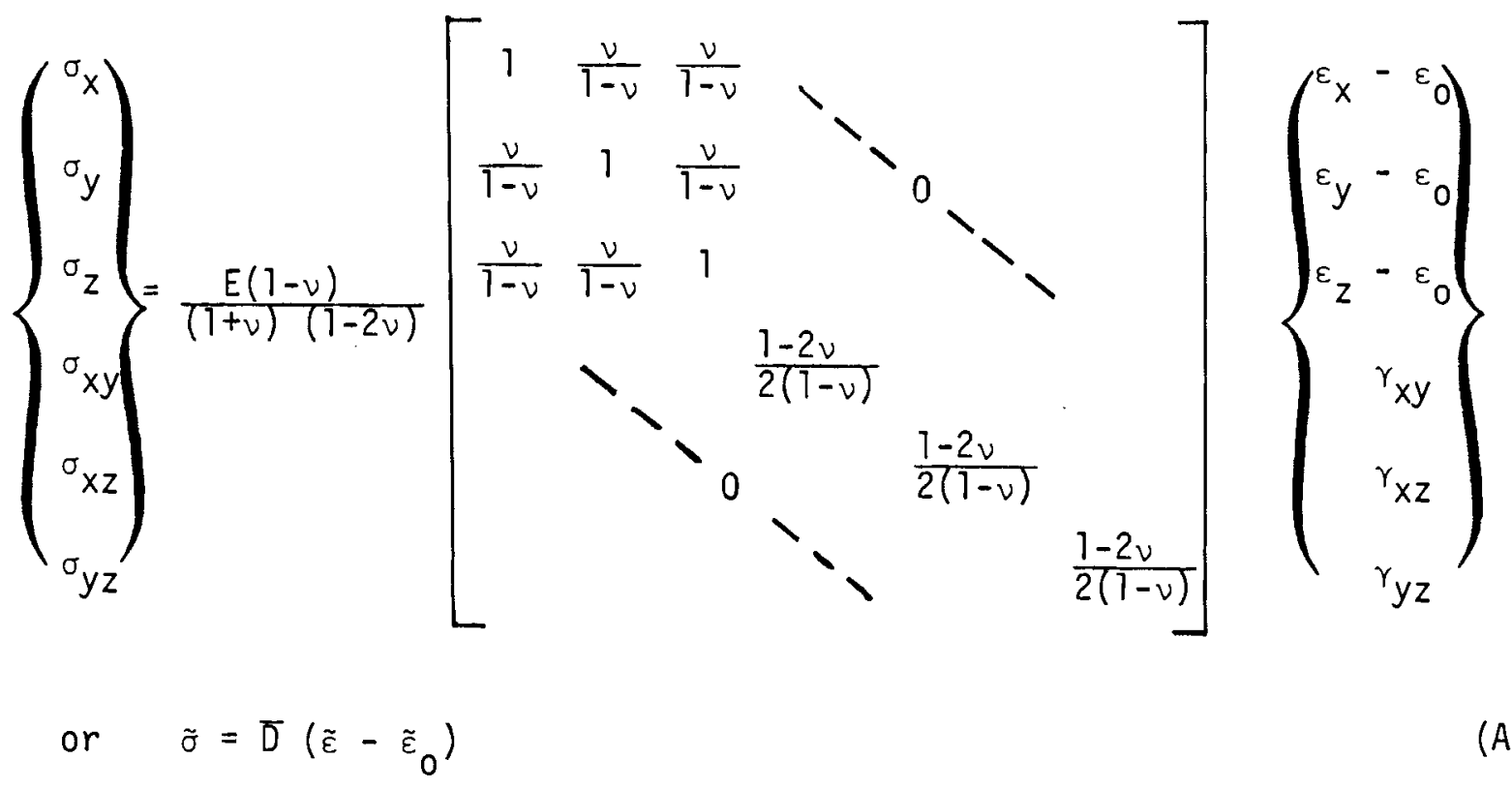

where

$$
\begin{aligned}
\tilde{\sigma}^{\top} & \left.=L \sigma_{x}, \sigma_{y}, \sigma_{z}, \sigma_{x y}, \sigma_{x z}, \sigma_{y z}\right\rfloor \\
\tilde{\varepsilon}^{\top} & \left.=L \varepsilon_{x}, \varepsilon_{y}, \varepsilon_{z}, \gamma_{x y}, \gamma_{x z}, \gamma_{y z}\right\rfloor \\
\tilde{\varepsilon}_{0}^{\top} & \left.=L \varepsilon_{0}, \varepsilon_{0}, \varepsilon_{0}, 0,0,0\right]
\end{aligned}
$$

The strain energy density, $U$, for this formulation takes the form

$$
\begin{aligned}
& U=\frac{1}{2} \tilde{\sigma}^{\top}\left\lfloor\tilde{\varepsilon}-\tilde{\varepsilon}_{0}\right\rfloor \\
& U=\frac{1}{2} \tilde{\varepsilon}^{\top} \bar{D} \tilde{\varepsilon}-\tilde{\varepsilon}^{\top} \bar{D} \tilde{\varepsilon}_{0}+\frac{1}{2} \tilde{\varepsilon}_{0}^{\top} \bar{D} \tilde{\varepsilon}_{0}
\end{aligned}
$$


The potential energy formulation will now be given and described for an elastic porous body. The exterior surfaces of the body are assumed to be coated with a nonporous membrane loaded with a normal traction of magnitude Pf directed in the outward sense. This corresponds to the condition of a sealed body with pressure of magnitude $P$ applied in the pores and equal in all directions. An immersed boundary would be treated by applying in addition, an inward pressure load of magnitude $P$.

The potential energy expression for the elastic porous body takes the form (Langhaar, 1962).

$$
\begin{aligned}
\pi= & \int_{v 01} U-\vec{G} \cdot \vec{v} d v o l-\int_{s} \vec{F} \cdot \vec{v} d s+\int_{v 01} \operatorname{grad}(P f) \cdot \vec{v} d v 01 \\
& -\int_{s} P f v_{n} d s
\end{aligned}
$$

The first volume integral represents the contribution of strain energy and applied loading interior to the porous body (with the exception of pressure forces) such as applied loads or gravity. Point or line loads applied to the interior would result in suitable singularity functions in $\vec{G}$. The first surface integral represents potential energy contribution by edge tractions. If the surface is totally immersed in a pressurizing fluid, then this integrand would be simply $-P v_{n}$ where $v_{n}$ is the displacement component (positive outward) to the surface. The second volume integral represents the potential energy contribution due to body forces caused by pressure gradients inside the porous body. The second surface integral represents potential energy contribution of internal pore pressure acting against the nonporous surface.

The form of equation $A .10$ while correct, does not reveal the true simplicity of poroelasticity. In particular, the analog between poroelastic and thermoelastic effects is somewhat hidden. 
In order to bring out this analog, the contribution to $\pi$ in A.10 due to porosity ( $f$ ) dependent terms must be analyzed. It should be mentioned that this includes not only the last two integrals of A.10 involving $f$ explicity but also the porosity dependent contribution to $U$ vide A.9, A.3, and A.2. This porosity dependent expression takes the form

$$
\pi^{\prime}=\int_{v_{01}}-\tilde{\varepsilon}^{\top} \bar{D}^{\top} \tilde{\varepsilon}_{0}^{\prime}+\operatorname{grad}(P f) \cdot \vec{v} d v o l-\int_{S} P f v_{n} d s+C
$$

where

$$
\tilde{\varepsilon}_{0}^{\prime}=\left[-\frac{P f(1-2 v)}{E},-\frac{P f(1-2 v)}{E},-\frac{P f(1-2 v)}{E}, 0,0,0\right]
$$

$C$ represents the displacement independent expression due to

$$
\tilde{\varepsilon}_{0}^{\top} \bar{D}^{\top} \tilde{\varepsilon}_{0} \text { in A.9. }
$$$$
\tilde{\varepsilon}^{\top}=\left[u_{x}, v_{y}, w_{z}, u_{y}+v_{x}, u_{z}+w_{x}, v_{z}+w_{y}\right]
$$
$x y z$ subscripts represent partial differentiation.

Substituting these expressions in A.11 yields

$$
\begin{aligned}
\pi^{\prime}= & \int_{v_{01}}\left(u_{x}+v_{y}+w_{z}\right) P f+\vec{v} \cdot \operatorname{grad}(P f) d v o l \\
& -\int_{s} P f v_{n} d s+C \\
\pi^{\prime}= & \int_{v_{01}} \operatorname{div}[(\vec{v}) P f] d v 01-\int_{s} P f v_{n} d s+C
\end{aligned}
$$


The volume and surface integrals of A. 13 vanish by application of the divergence theorm. Thus, the porosity dependent contribution yields only a constant contribution to the potential energy of the porous elastic body.

Thus, the displacement dependent potential energy expression becomes

$$
\bar{\pi}=\int_{\text {vol }} \frac{1}{2} \tilde{\varepsilon}^{\top} \bar{D}^{\top} \tilde{\varepsilon}^{\top}-\tilde{\varepsilon}^{\top} \bar{D}^{\top} \tilde{\varepsilon}_{0}{ }^{*}-\vec{G} \cdot \vec{v} \text { dvol }-\int_{S} \vec{F} \cdot \vec{v} d s
$$

where $\tilde{\varepsilon}_{0}{ }^{* T}=\left[\frac{P(1-2 v)(1-\beta)}{E}+\alpha T\right]\left[\begin{array}{llllll}1 & 1 & 1 & 0 & 0 & 0\end{array}\right]$

Stress strain relations in terms of $\tilde{\varepsilon}_{0}{ }^{*}$ become

$$
\tilde{\sigma}=\bar{\delta}\left\{\tilde{\varepsilon}-\tilde{\varepsilon}_{0}^{*}\right\}+\left\{\begin{array}{l}
\mathrm{Pf} \\
\mathrm{Pf} \\
\mathrm{Pf} \\
0 \\
0 \\
0
\end{array}\right\}
$$

Comparison of equations A.14 through A. 16 reveals that the initial strain formulation of poroelasticity is analogus to a thermoelastic formulation with the exception that additional initial strain contribution $P(1-2 v)(1-\beta) / E$ must be included with the aT initial strain for thermoelastic formulations. In addition, from A.16, an additional normal tensile stress of magnitude Pf must also be added in recovering stresses from strains.

The derivation just presented was meant to show the variational equivalence of poroelastic and thermoelastic formulations. Since the discussion was along variational lines, $i$ ts results are independent of any choice of coordinate systems. A rectilinear cartesian coordinate system was chosen strictly as a convenience. 
For applications dealing with compressed air energy storage, it is enlightening to consider the relative strain affects due to thermal expansion $(\alpha T)$ and pore pressure $P(1-2 v)(1-\beta) / E$ in equation $A .15$. Using an average pressure of $4.5 \mathrm{MPa}$ and an average temperature increase of $100^{\circ} \mathrm{C}$ along with elastic parameters shown in Section 3, it can be shown that pore pressure effects are only about $6 \%$ of the initial strain caused by thermal effects. 
APPENDIX B

Finite Element Programming

Computational results presented in this report were obtained by using a modified version of the ADINA computer program (Bathe, 1977 and Bathe, 1976). ADINA (Automatic Dynamic Incremental Nonlinear Analysis) is a general purpose proprietary finite element program developed and distributed by Klaus Bathe (MIT). The modifications were of a minor nature and dealt with modifying a linear thermoelastic two-dimensional material model to include the effects of pore pressure. In addition, output features were added so that an independent plotting program could be used for processing results.

ADINA was used to analyze the two-dimensional axisymmetric model shown in Figure 3 . A total of 270 parabolic isoparametric elements were used in constructing this mesh. Figure B.1 illustrates the nodal

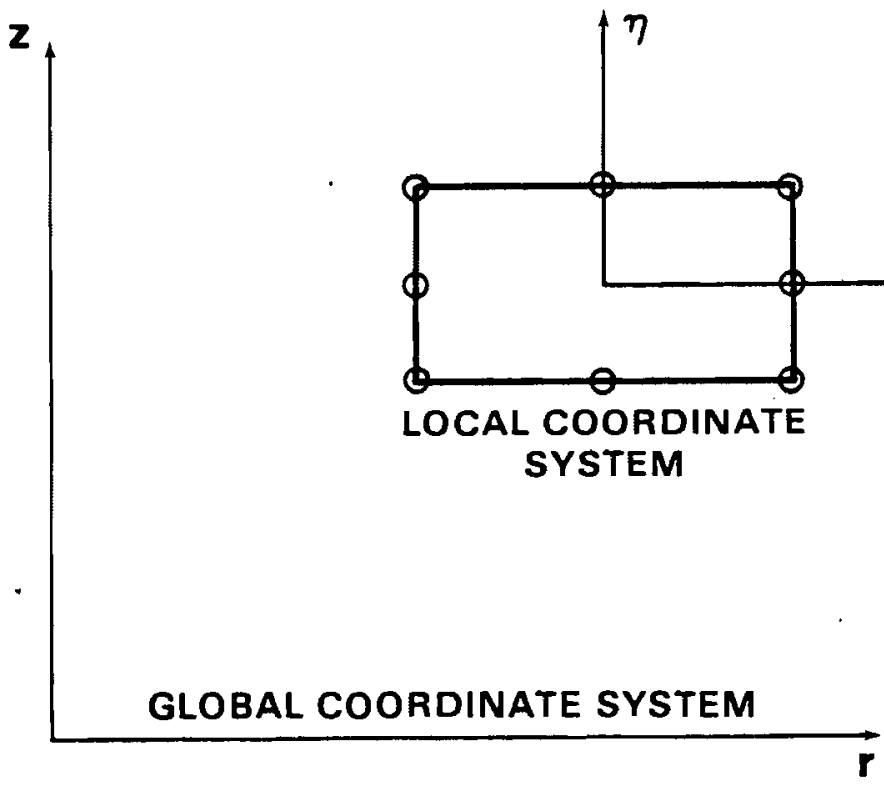

FIGURE B.1 Coordinate Systems and Nodal Locations Used for Formulating Element Properties 
configurations and element coordinates used in formulating element properties. Derivations of element stiffness characteristic are available in the literature and will not be given here (Zienkiewicz, 1977 and Cook, 1974).

Displacements interior to each element in the $r, z$ directions are expressed in terms of corresponding nodal displacements. These interpolation functions (or shape functions as they are commonly called) are then used as an expansion basis for the purposes of formulating quadratic expressions for the potential energy contribution due to the element's $r z$ domain. The corresponding potential energy for the entire domain (see Appendix $A$ ) is thus expressable as a quadratic functional of the model nodal displacements. Minimization of this quadratic functional with respect to nodal displacements yields a set of simultaneous algebraic equations the solution of which represents the approximate solution. 


\section{DISTRIBUTION}

No. of

Copies

OFFSITE
A. A. Churm
DOE Chicago Patent Group
Chicago Operations Office
9800 South Cass Avenue
Argonne, IL 60439

\section{7}

\section{DOE Technical Information Center}

\section{B. J. Mueller Department of Energy Chicago Operations Office 9800 S. Cass Avenue Argonne, IL 60439 \\ Chief, APMBR \\ Division of Energy Storage Sys tems \\ U.S. Department of Energy \\ Washington, DC 20585 \\ Dan Hall \\ P.0. 635 \\ Fairvault, MN 55021 \\ Royal B. Newman \\ Soyland Power Cooperative, Inc. PO Box A1606 \\ Decatur, IL 62525}

G. D. Pezdirtz, Director

Division of Energy Storage Sys tems

U.S. Department of Energy Washington, DC 20585

5 Gabor D. Karadi

Department of Energy

Division of Energy Storage

600 E Street, Room 416

Washington, DC 20545
No. of

Copies

5 Saul Strauch

DOE Division of Energy Storage Sys tems

Advanced Physical Methods

Branch

600 E Street, Room 416

Washington, DC 20585

J. H. Swisher

Division of Energy Storage Systems

U.S. Department of Energy Washington, DC 20585

D. W. Boehm

Division of Environmental

Control Technology

U.S. Department of Energy

Washington, DC 20585

Assistant Director for Major Projects

Division of Solar Energy

U.S. Department of Energy

Washington, DC 20585

Assistant Director for Thermal

Power Systems

Division of Solar Energy

U.S. Department of Energy

Washington, DC 20585

DOE Library

U.S. Department of Energy

Mail Station G-043

Washington, DC 20585

R.F. Kimberlin

DOE Library

U.S. Department of Energy

Room 1223

Washington, DC 20585 
No. of

Copies

D. Willett

Acres American, Inc.

Liberty Bank Building

Main at Court

Buffalo, NY 14202

L. A. Wilson

Middle South Services

P.0. Box 61000

New Orleans, LA 70161

G. T. Flynn

Energy Systems Engineer

MIT/Lincoln Laboratory

Lexington, MA 02173

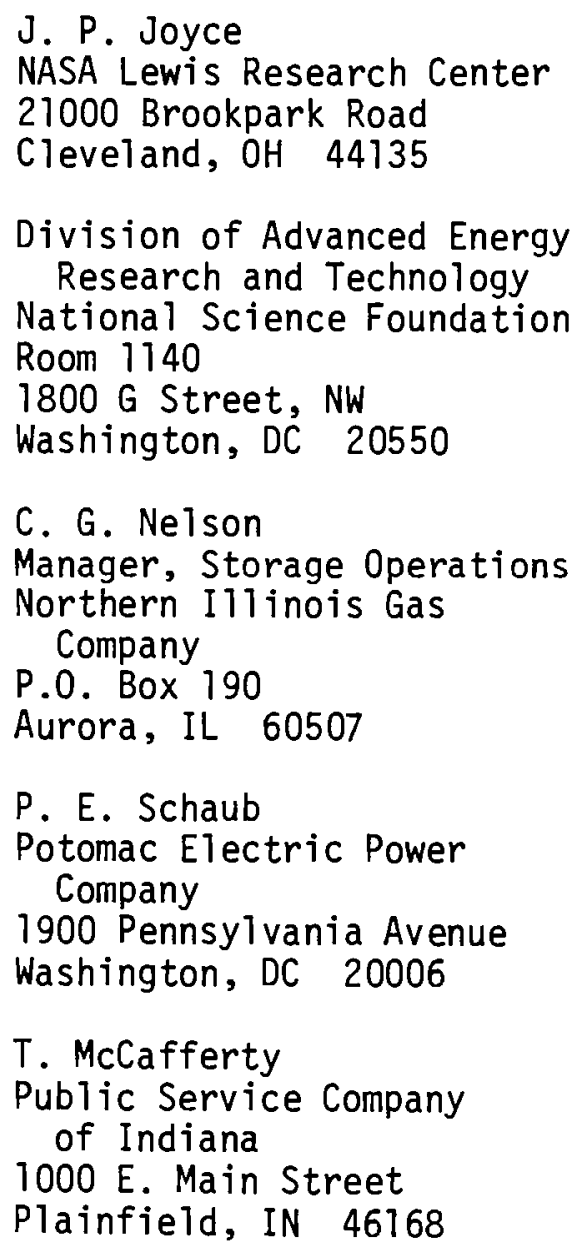

No. of

Copies

2 Technical Library

Department 3141

Sandia Laboratory

Albuquerque, NM 87115

J. Rasmussen

PEPCO

1900 Pennsylvania Avenue, N.W. Washington, DC 20068

\section{S. Serata}

Serata Geomechanics, Inc.

1229 Eighth Street

Berkeley, CA 94710

Energy Research Section

Tennessee Valley Authority 1360 Commerce Union Bank Bldg. Chattanooga, TN 37401

Gerald Phillips

Tennessee Valiey Authority

1150 Chestnut, Tower 2

Chattanooga, TN 37401

E. Berman

Technical Library

TRW Energy Systems Group

7600 Colshire Drive

McLean, VA 22101

E. H. King

Underground Design Consultants 820 Cascade B1dg.

Portland, OR 97204

A. I. Giramonti

United Technologies Research Center

Silver Lane

East Hartford, CT 06108

H. J. Pincus

University of Wisconsin

Department of Geological Sciences

Sabin Hall and Greene Museum P.0. Box 413

Milwaukee, WI 53201 
No. of

Copies

D. Ayers

Manager, Fluid Systems

Laboratory

Westinghouse Electric

Corporation

1291 Cumberland Avenue

West Lafayett, IL 47906

American Public Power

Association

2600 Virginia Avenue, NW

Washington, DC 20037

2 J. M. Clinch

Argonne National Laboratory

9700 South Cass Avenue

Argonne, IL 60439

Manager, Research and Development

Bonneville Power Administration

P.0. Box 3621

Portland, OR 97208

Research Library, Reference Section

Information Division

Brookhaven National Laboratory

Upton, NY 11973

Stanley Stys

Vice President, American

Brown Boveri Corporation

New Brunswick, NJ 08902

Director of Research

Cincinnati Gas and and Electric Company

139 East Fourth Street

Cincinnati, $\mathrm{OH} 45202$

D. E. DeViney

Commonwealth Edison Company

1319 South First Avenue

Maywood, IL 60153
No. of

Copies

R. A. Bell

Consolidated Edison Company

4 Irving Place

New York, NY 10003

T. Schneider

Electric Power Research

Institute

Box 10412

Palo Alto, CA 94303

D. Anderson

Fenix and Scisson, Inc.

P.0. Box 15609

Tulsa, OK 74115

Director of Research

GPU Service Corporation

260 Cherry Hill Road

Parsippany, NJ 07054

A. H. Barber

Director of Marketing

Harza Engineering Company

$150 \mathrm{~S}$. Wacker Drive

Chicago, IL 60606

Library

Lawrence Berkeley Laboratory

University of California

B7dg. 50, Room 134

Berkeley, CA 94720

3 Technical Information Department, L-3

Lawrence Livermore Laboratory

University of California

P.0. Box 808

Livermore, CA 94550

Director of Research

Louisiana Power and Light

142 Delaronde Street

New Orleans, LA 70174 
No. of

Copies

I. Glendenning Head of Long-Term Studies

Marchwood Engineering Labs

Southampton, England

\section{A. Ferreira \\ Electric Power Research Institute \\ NEPLAN \\ 174 Brush Hill Avenue \\ West Springfield, MA 01089}

W. Stevens

Project Manager

Electric Power Research Institute

3412 Hillview Avenue

PO Box 10412

Palo Alto, CA 94303

Fred Ahrens

Argonne National Laboratory 9700 South Cass Avenue

Argonne, IL 60439

Paut Gnirk

$\mathrm{Re} / \mathrm{Spec}$ Inc.

PO Box 725

Rapid City, SD 57701

Donald L. Katz

Department of Chemical

Engineering

The University of Michigan

2042 E. Engr. B1dg.

Ann Arbor, MI 48109

R. L. Thoms

Louisiana State University

Institute for Environmental Studies

Room 42, Atkinson Hall

Baton Rouge, LA 70803
No. of

Copies

O.C. Farquhar

U. of Massachusetts

Dept. of Geology \& Geography

Morrill Science Center

Amherst, MA 01003

T. L. Brekke

University of California

Department of Civil Engineering

1847 Yosemite Road

Berkeley, CA 94707

H. Lorenzen

PB-KBB Inc.

Subservice Systems \& Technology 800 Commerce Road West

Harahan, LA 70123

A. H. Warnke

Vice President Power Supply

Central Illinois Public Service Co.

607 East Adams Street

Springfield, IL 62701

$M r$. G. E. Huck

Manager of Planning

I1] ino is Power Company

500 South 27th St.

Decatur, IL 62525

Mr. W. C. Walke

Project Manager

Sargent \& Lundy Engineers

55 East Monroe Street

Chicago, IL 60603

T. J. Maiman

Sta. Mech. Engr. Dept. Manager

Commonwealth Edison Co.

36 FN West

PO Box 767

Chicago, IL 60690

E. M. Mabuce

Manager-Applied Research

Corporate Planning Dept.

Union Electric Co.

PO Box 149

St. Louis, MO 63766 
No of

Copies

W. F. Kobett

CAES Project Manager

Westinghouse Electric Corp.

Combustion Turbine Sys. Div.

Long Range Development-Lab 100

PO Box 251

Concordville, PA 19331

J. C. Smith

Division of Electrical Energy Systems

Department of Energy

20 Massachusetts Ave, Room 2205

Washington, DC 20545

J. Gahimer

Department of Energy

600 "E" Street

Washington, DC 20545

C. Holt

Battelle Columbus Laboratories

505 King Avenue

Columbus, $\mathrm{OH} 43201$

T. Barlow

Lawrence Livermore Laboratory

PO Box 808

Livermore, CA 94550

M. Dodd

Organization 5743

Sandia Labs

Albuquerque, NM 87115

R. 0 . Woods

Sandia Laboratories

Org. No. 4715

Albuquerque, NM 87115

J. L. Nash-Webber

MIT

Energy Lab

Cambridge, MA 02139
No. of

Copies

ONSITE

DOE Richland Operations

Office

D. K. Jones

H. E. Ransom

Pacific Northwest Laboratory

R.D. Allen

M.C.C. Bampton

T.J. Doherty

D.W. Dragnich

M.K. Drost

R.L. Erikson

J.A. Fort

J.R. Friley (5)

P.J. Gutknecht

A.J. Haverfield

J.J. Jacobson

L.D. Kannberg

W.V. Loscutoff (30)

R.A. McCann

M.A. McKinnon

L.T. Pedersen

R.W. Reilly

R.P. Smith

J.A. Stottlemyre

A.M. Sutey

D.S. Trent

L.E. Wiles

Technical Information (5)

Publishing Coordination (2) 


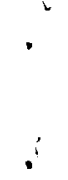

